\title{
Synthesis Study of Precursor Mixture of verdantiol, aurantiol and lyrame Schiff Base and Its Characterization Using GC-MS
}

\author{
CANDRA IRAWAN ${ }^{1}$, DIAN ISLAMIYATI', ANDITA UTAMI"*, \\ RIKA PERDANA PUTRI ${ }^{2}$ and SINGGIH WIBOWO1
'Department of Chemical Analysis, Politeknik AKA Bogor, Jalan Pangeran Sogiri, Tanah Baru, Bogor 16154, Indonesia.
${ }^{2} \mathrm{PT}$. Nilam Widuri Bogor, Jalan Raya Tlanjung Udik, Cibinong, Indonesia.
${ }^{*}$ Corresponding author E-mail: andita @ kemenperin.go.id \\ http://dx.doi.org/10.13005/ojc/350347
}

(Received: April 29, 2019; Accepted: June 18, 2019)

\begin{abstract}
A mixture of verdantiol, aurantiol, and lyrame based schiff base precursors has been prepared by a simple condensation method. The mixture product has been characterized by gas chromatography and mass spectrophotometer (GC-MS). The color of product has been compared with the standard of the mentioned schiff base which was confirmed as yellow colored solution. The lyrame was not detected and the verdantiol showed as the most obtained product.
\end{abstract}

Keywords: Schiff base, Mixture, GC-MS, Fragrance.

\section{INTRODUCTION}

Perfume is one of chemical products which is used in daily life by men and women. ${ }^{1}$ In its production process, raw materials such as fragrances are needed. ${ }^{2,3}$ Fragrances are pure aroma oil or extracted oil from aroma compound which has not been added by alcohol or other chemicals. ${ }^{4}$ Therefore, the smell of these compounds is very strong and the form is like an oil. ${ }^{4}$ Raw material of this natural aroma depends on the result of natural products and weather condition. Consequently, many perfume producers have been developing synthetic aroma compound which can be easily produced continuously. ${ }^{5}$
Synthetic raw material are is used in the production of aroma compounds is Schiff base. Schiff base is an aldehyde- or ketone-like compound in which the carbonyl group is replaced by an azomethine or imine group. ${ }^{6-8}$ The advantage of using schiff base is its specific aroma characteristic and long-lasting, hence it can improve the quality of aroma compound. ${ }^{9,10}$ There are several types of schiff bases such as lilyantine, jasmea, verdantiol, aurantiol, lyrame dan cyclantine. ${ }^{11}$ Verdantiol, aurantiol and lyrame are a popular schiff bases which are used in the production of flower aroma compounds. ${ }^{12}$

In order to produce verdantiol, aurantiol

This is an Open Access article licensed under a Creative Commons license: Attribution 4.0 International (CC- BY). Published by Oriental Scientific Publishing Company @ 2018 
and lyrame Schiff base, methyl anthranilate is mixed with lilyall, hydroxycitronellal, and lyral, respectively. ${ }^{13}$ In the previous studies, our group has synthesized lyrame Schiff base using a simple condensation method at the temperature of $110^{\circ} \mathrm{C}$ for $30 \mathrm{~min}$ and has characterized the product using GC-MS. ${ }^{14}$ Our group has also observed the effect of synthesis time to obtain aurantiol Schiff base and we found that the best time was around 30 to 60 minute..$^{15}$ In the present study, we combined the precursor of mentioned three schiff bases to produce schiff base and observed the product using GC-MS. We tried to find out which schiff base would be highly produced.

\section{METHODS}

\section{Synthesis of Schiff Base Mixture}

Methyl anthranilate solution, lilyall solution, lyral solution, hydroxycitronellal solution and ethanol $99 \%$ are used as the precursors of schiff bases. The mixture solution was heated and stirred at temperature about $110 \pm 5^{\circ} \mathrm{C}$ for 30 minutes.

\section{Color Test of Schiff Base Mixture}

The product solution is poured into a tube that is $1.3 \mathrm{~cm}$ in diameter and $10 \mathrm{~cm}$ high to a specified limit of $\pm 1 \mathrm{~cm}$. Color observation is carried out by the panelist from the front of the tube and parallel to the eye. The picture is taken in a place that has enough light, avoids the reflection of light, and the base is white.

\section{Characterization using GC-MS}

Schiff base confirmation using gas chromatography mass spectrometer (GC-MS) Agilent 5975C. Schiff base confirmation was carried out by interpretating based on MS data. Then, fragmentation pattern was made to explain the reaction mechanism. The analysis on condition of GC-MS could be seen at Table 1 below.

Table 1: GC-MS Analysis Condition ${ }^{14}$

\begin{tabular}{lc}
\hline & Information \\
\hline Column & $\begin{array}{c}\text { Capillary Column : HP }-5(5 \% \\
\text { Phenyl Methyl Siloxane } 325^{\circ} \mathrm{C} \\
\text { Carrier Gas }\end{array}$ \\
Carrier Gas Pressure & $7,0531 \mathrm{psi}$ \\
Injection Technique & Split \\
Injector Temperature & $100^{\circ} \mathrm{C}$ \\
Injection Volume & $0,2 \mathrm{~L}$ \\
Split Ratio & $80: 01: 00$ \\
Temperature Program (Column) & \\
Initial Temperature & $100^{\circ} \mathrm{C}$ hold for $5 \mathrm{~min}$ \\
Temperature rate & $15^{\circ} \mathrm{C}$ per min \\
Final Temperature & $250^{\circ} \mathrm{C}$ hold for 5 min \\
\hline
\end{tabular}

\section{RESULTS AND DISCUSSION}

The obtained product was displayed in Fig. 1 which also exhibited the color of the standard of verdantiol, aurantiol and lyrame schiff base as a comparison. It is noted that the obtained product showed the weakest color among the others.

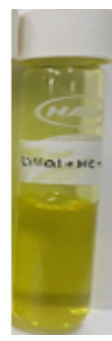

(a)

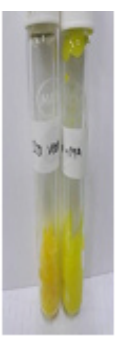

(b)

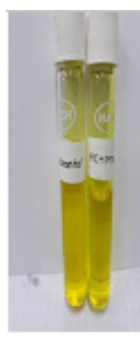

(c)

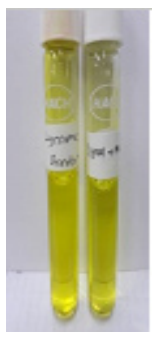

(d)
Fig. 1. Color comparison of (a) mixture, (b) verdantiol standard, (c) aurantiol standard, and (d) lyrame standard

The three Schiff bases pass through the reaction of crossed aldol condensation. The reaction of crossed aldol condensation will occur when an aldehyde or ketone without $\alpha$-hydrogen is mixed with aldehyde which has $\alpha$-hydrogen. The reaction between aldehyde with a primary amine will produce an imine as its product that is a compound having a $\mathrm{C}=\mathrm{N}$ group. ${ }^{16}$

Confirmation of the schiff base formation was carried out by GC-MS. The GC result of the mixture is shown in Table 2.

Table 2: The GC result of mixture

\begin{tabular}{cccc}
\hline $\begin{array}{c}\text { Retention } \\
\text { Time (Min) }\end{array}$ & Compounds & Compotition (\%) & $\begin{array}{c}\text { Molecular } \\
\text { Formula }\end{array}$ \\
\hline 8.679 & Hydroxycitronellal & 14.99 & $\mathrm{C}_{10} \mathrm{H}_{20} \mathrm{O}_{2}$ \\
9.458 & Methyl Anthranilate & 4.45 & $\mathrm{C}_{8} \mathrm{H}_{9} \mathrm{NO}_{2}$ \\
11.4 & Lilyall & 32.64 & $\mathrm{C}_{14} \mathrm{H}_{20} \mathrm{O}$ \\
12.512 & Lyral & 5.06 & $\mathrm{C}_{13} \mathrm{H}_{22} \mathrm{O}_{2}$ \\
12.571 & Lyral & 17.98 & $\mathrm{C}_{13} \mathrm{H}_{22} \mathrm{O}_{2}$ \\
16.628 & Verdantiol & 5.8 & $\mathrm{C}_{22} \mathrm{H}_{27} \mathrm{NO}_{2}$ \\
20.103 & Verdantiol & 2.42 & $\mathrm{C}_{22} \mathrm{H}_{27} \mathrm{NO}_{2}$ \\
23.696 & Verdantiol & 6.18 & $\mathrm{C}_{22} \mathrm{H}_{27} \mathrm{NO}_{2}$ \\
16.916 & Aurantiol & 3 & $\mathrm{C}_{18} \mathrm{H}_{27} \mathrm{NO}_{3}$ \\
16.981 & Aurantiol & 5.41 & $\mathrm{C}_{18} \mathrm{H}_{27} \mathrm{NO}_{3}$ \\
18.137 & Aurantiol & 2.06 & $\mathrm{C}_{18} \mathrm{H}_{27} \mathrm{NO}_{3}$ \\
\hline
\end{tabular}

The result indicated that there were only three verdantiol isomers and three aurantiol isomers formed as product. Based on the structure, there should be six verdantiol isomers and four aurantiol isomers obtained from the condensation reaction. This result might be caused by the competition 
reaction where reactive isomers would be easily formed.

From Table 2, verdantiol was the most obtained schiff base because it has aromatic group in lilyall compound which attracts electrons. ${ }^{16}$ The aromatic group will affect the closest carbon atom to carbonyl becoming electron-poor so that $\alpha$-hydrogen becomes more acid. Then, lilyall will be faster to react with amine group in methyl anthranilate which is a base. The competition reaction between mixed raw material with amine in methyl anthranilate caused the most acid aldehyde becoming more reactive to amine. Lyrame could not be detected due to lyral as its precursor was the weakest base among other evaluated compounds. The schiff base precursor mixture was analyzed using MS to confirm the compounds in the product as shown in Figure 2.

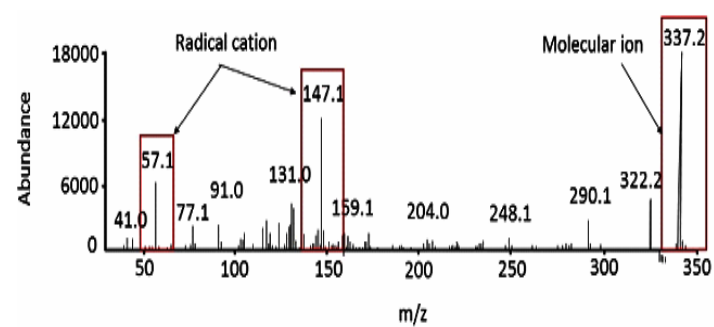

(a)

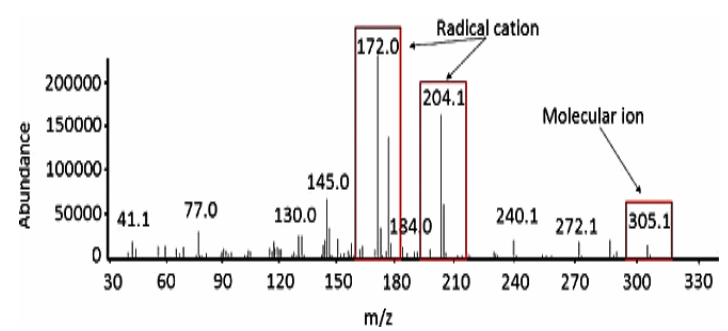

(b)

Fig. 2. Mass spectra of (a) verdantiol and (b) aurantiol in the schiff base mixture

In Fig. 2 (a), molecular ion at $\mathrm{m} / \mathrm{z} 337.2$ is equal to the molecular weight of verdantiol schiff base of $337.47 \mathrm{~g} / \mathrm{mol}$. Furthermore, the fragmentation result fragmentation obtained ion at $\mathrm{m} / \mathrm{z} 147$ and 57 as seen in Fig. 3 (a). Fig. 3 (b) showed molecular ion $\left(\mathrm{M}^{+}\right)$of aurantiol schiff base (Methyl-N-3,7-dimethyl7-hydroxyoctylidene anthranilate) at $\mathrm{m} / \mathrm{z} 305.1$ which is equal to the molecular weight of aurantiol schiff base of $305.42 \mathrm{~g} / \mathrm{mol}$. The highest peak at m/z 172.0 and the peak at $\mathrm{m} / \mathrm{z} 204.1, \mathrm{~m} / \mathrm{z} 287, \mathrm{~m} / \mathrm{z} 272$ are cation radicals as displayed in Figure 3 (b).

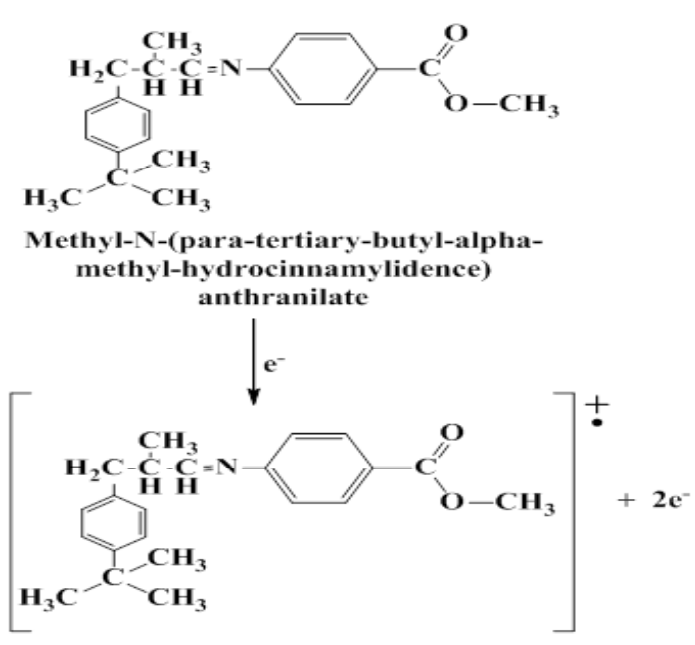

$\mathbf{m} / \mathbf{z}=337$

Ion Molekul Methyl-N-(para-tertiary-butylalpha-methyl-hydrocinnamylidence) anthranilate

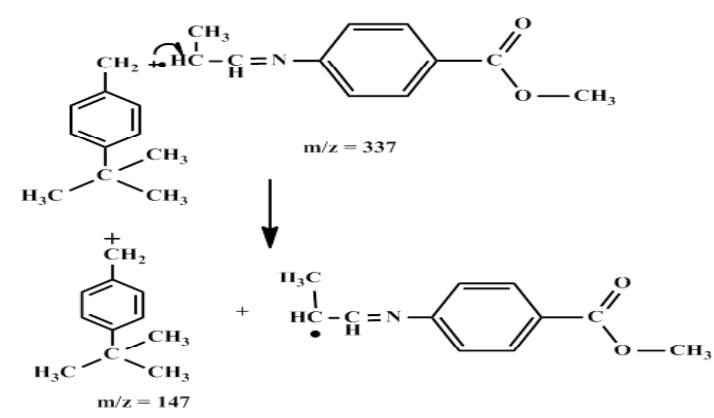

(a)<smiles>COC(=O)c1ccc(N=CC(C)C(C)(C)C(c2ccccc2)C(C)C)cc1</smiles>

(b)

Fig. 3. Fragmentation of (a) verdantiol and (b) aurantiol

\section{CONCLUSION}

Based on the experiment results, schiff base precursor mixture had lighter yellow color than the standard of verdantiol, aurantiol and lyrame. The MS results showed that verdantiol as cyclic compound and aurantiol peaks at $\mathrm{m} / \mathrm{z} 337.2$ and 305.1 , respectively. Verdantiol was the most obtained 
product while lyrame was not detected due to the competition reaction.

\section{ACKNOWLEDGMENT}

We would like to thank Politeknik AKA
Bogor to fully support our research and PT Nilam Widuri for helping us during the experiments.

\section{Conflict of Interest}

The authors declare that they have no conflict of interest.

\section{REFERENCES}

1. Gherghel, S.; Morgan, R. M.; Blackman, C. S.; Karu, K.; Parkin, I. P. Science \& Justice., 2016, 56, 413.

2. Villa, C.; Gambaro, R.; Mariani, E.; Dorato, S. Journal of Pharmaceutical and Biomedical Analysis., 2007, 44, 755.

3. Herman, S. J. Fragrance Applications: A Survival Guide., 1 edn., Allured Pub Corp. 2001.

4. Vankar, P. S. Resonance., 2004, 9, 30-41.

5. Sarkic, A.; Stappen, I. Cosmetics., 2018, 5, 11.

6. da Silva, C. M.; da Silva, D. L.; Modolo, L. V.; Alves, R. B.; de Resende, M. A.; Martins, C. V. B.; de Fátima, Â. Journal of Advanced Research., 2011, 2, 1.

7. Raikwar, K.; Agarwal, D. D. Orient. J. Chem., 2015, 31, 547.

8. Dhokale, N. T.; Karale, B. K.; Nagawade, A. V. Orient. J. Chem., 2017, 33, 165.

9. Quellet, C.; Schudel, M.; Ringgenberg, R.
CHIMIA International Journal for Chemistry., 2001, 55, 421.

10. Gygax, H.; Koch, H. CHIMIA International Journal for Chemistry., 2001, 55, 401.

11. Pybus, C.; Sell, C. The Chemistry of Fragrances: From Perfumer to Consumer., 2 edn., 2006,

12. Ohloff, G. Scent and fragrances. The fascination of odors and their chemical perspectives., Springer-Verlag, Berlin., 1994.

13. Arctander, S. Perfume and flavor chemicals (aroma chemicals)., Montclair, N.J., 1969.

14. Irawan, C.; Islamiyati, D.; Putri, R. P.; Madiabu, M. J.; Supriyono. Orient. J. Chem., 2018, 34, 3118.

15. Irawan, C.; Indriyati, S.; Lestari, E. S.; Hidaningrum, A.; Supriyono. Orient. J. Chem., 2018, 34, 394.

16. Fesenden, R. J.; Fesenden, J. S. Organic Chemistry., 2 edn, Willard Grant Press, Boston, Massachusetts., 1982, 